Article

\title{
Effect of Mechanobiology of Cell Response on Titanium with Multilayered Aluminum Nitride/Tantalum Thin Film
}

\author{
Mao-Suan Huang ${ }^{1,2}$, Shang-Yang Yu ${ }^{1,+}{ }^{+}$Pao-Chang Chiang ${ }^{3,4}$, Bai-Hung Huang ${ }^{5,6}$, \\ Takashi Saito ${ }^{7} \mathbb{D}_{\text {, Chien-Chia Huang }}{ }^{\text {, Fang-Tzu Pai }}{ }^{8}$, Chia-Yu Wu ${ }^{3,9, *}$ and Wen-Chien Lan 10,* \\ 1 Department of Dentistry, Taipei Medical University-Shuang Ho Hospital, New Taipei City 235, Taiwan; \\ hms4837@tmu.edu.tw (M.-S.H.); arccomet@hotmail.com (S.-Y.Y.) \\ 2 School of Oral Hygiene, College of Oral Medicine, Taipei Medical University, Taipei 110, Taiwan \\ 3 School of Dentistry, College of Oral Medicine, Taipei Medical University, Taipei 110, Taiwan; \\ m204095009@tmu.edu.tw \\ 4 Dental Department of Wan-Fang Hospital, Taipei Medical University, Taipei 116, Taiwan \\ 5 Asia Pacific Laser Institute, New Taipei City 220, Taiwan; babyfireh@gmail.com \\ 6 Implant Academy of Minimally Invasive Dentistry, Taipei 106, Taiwan \\ 7 Division of Clinical Cariology and Endodontology, Department of Oral Rehabilitation, School of Dentistry, \\ Health Sciences University of Hokkaido, Hokkaido 061-0293, Japan; t-saito@hoku-iryo-u.ac.jp (T.S.); \\ courageev@hotmail.com (C.-C.H.) \\ 8 School of Dental Technology, Taipei Medical University, Taipei 110, Taiwan; M249108004@tmu.edu.tw \\ 9 Division of Oral and Maxillofacial Surgery, Department of Dentistry, Taipei Medical University Hospital, \\ Taipei 110, Taiwan \\ 10 Department of Oral Hygiene Care, Ching Kuo Institute of Management and Health, Keelung 203, Taiwan \\ * Correspondence: borgiawu@gmail.com (C.-Y.W.); jameslan@ems.cku.edu.tw (W.-C.L.) \\ + Co-first author: Shang-Yang Yu.
}

Received: 19 November 2019; Accepted: 13 January 2020; Published: 16 January 2020

\begin{abstract}
In the present study, the piezoelectric aluminum nitride (AlN)/tantalum (Ta) (PAT) thin film was investigated as a biocompatible film and osseointegrated with biomedical devices such as implants. The stress variation on the interaction of cells with the PAT surface was investigated using osteoblast-like cells (MG-63) and fibroblast cells (NIH3T3). A singular behavior was observed on the PAT film with a (002) texture, in which the MG-63 cells were more dispersed and displayed longer and more filopodia than the NIH3T3 cells. Moreover, the MG-63 cells showed ingrowth, adherence, and proliferation on the PAT film surface. The MG-63 cells had more obvious stress variation than the NIH3T3 cells in the differentiation and proliferation. The mechanobiological reaction to cell differentiation and proliferation not only caused osseointegration, but also reduced the surface activation energy, thus enhancing bone remodeling. The formation of a nanopolycrystalline PAT film is believed to enhance the mechanobiological effect, promoting osseointegration.
\end{abstract}

Keywords: aluminum nitride; piezoelectric film; mechanobiological effect; stress variation

\section{Introduction}

Recently, numerous methods have been used to modify implant surfaces to enhance the speed of bone healing [1-10]. It was found that osseointegration could be effectively promoted by surface modification $[1,2,4,11,12]$. The osseointegration time is a crucial factor in clinical cases, for example, patients with submerged implants and devices. However, invasive detection is not suitable for sensing stability on the osseointegration of submerged implants. The voltage-driven full Wheatstone bridge configuration is a traditional instrumentation system, which is applied to quantify strain gauges. While 
there is a disadvantage of low-power for submerged implantology applications [13]. Accordingly, it is very important to fabricate bioactive surfaces on implants and monitoring osseointegration for biomedical engineering.

According to previous studies [11,14], aluminum nitride (AlN), as a biosensing film, performed effective sensing for fibroblast cell (NIH3T3) and for the biophysical detection of implants. However, the biological reaction of bone cells is a critical factor in bone remolding and enhancing osseointegration. Furthermore, the effects of molecules and cells on the osseointegration of bone implants include factors affecting bone formation [15] and bone adsorption [16]. Numerous studies have shown that growth factors, matrix molecules, or stem cells can be used to facilitate bone healing and regeneration in implants [17-20]. Predictable bone regeneration after a pathological bone loss in implants, a solution to reduce bone loss, and accelerated healing at the site of traditionally poor prognosis as well as simultaneous enlargement and implant placement, may become clinical realities. Biologic approaches such as molecular imaging define a research method. Nevertheless, these strategies are intrinsically linked to biomechanical factors.

As stated above, developing a new method to realize the reaction of bone cells is important. Therefore, the study was to fabricate a promising biosensing approach to detect bone-cell integration such as (osteoblast-like MG-63) with the piezoelectric AlN/Ta (PAT) thin film, and the reaction between them. The measurement of stress variation was utilized to analyze the reaction between the bone cells and the PAT thin film.

\section{Materials and Methods}

\subsection{Preparation of the Investigated Specimens}

The radio-frequency magnetron sputtering system with the $\mathrm{Al}$ target $(\Phi 20 \mathrm{~cm}$ and purity $99.99 \%)$, Ta target ( $\Phi 20 \mathrm{~cm}$ and purity $99.99 \%$ ), and $\mathrm{Cu}$ target ( $\Phi 20 \mathrm{~cm}$ and purity $99.99 \%$ ) were employed to fabricate the PAT thin film on the $\mathrm{Si}(100)$ wafer substrate. Before the deposition process, the $\mathrm{SiO}_{2}$ oxide layer with a thickness of $1000 \mathrm{~nm}$ was grown as a buffer at a temperature of $250{ }^{\circ} \mathrm{C}$ for $15 \mathrm{~min}$ under the plasma power of $20 \mathrm{~W}$, chamber running pressure of $5.0 \times 10^{-3} \mathrm{Torr}$, and $\mathrm{O}$ flow rate of $30 \mathrm{sccm}$. Subsequently, the $\mathrm{Cu}$ film was sputter deposited on the surface of $\mathrm{SiO}_{2}$ at a temperature of $400{ }^{\circ} \mathrm{C}$ for 15 min under the plasma power of $20 \mathrm{~W}$, chamber running pressure $5.0 \times 10^{-6}$ Torr, and Ar flow rate of $30 \mathrm{sccm}$. Hereafter, a thickness of a $10 \mathrm{~nm}$ Ta layer was sputter deposited on the surface of the $\mathrm{Cu}$ film at the same deposition conditions. Finally, the AlN film was homogeneously deposited on the Ta layer surface at a temperature of $400{ }^{\circ} \mathrm{C}$ for 15 min under the plasma power of $20 \mathrm{~W}$, chamber running pressure of $5.0 \times 10^{-6}$ Torr, and gas mixture ratio of $\mathrm{Ar} / \mathrm{N}_{2}$ (1:2). Therefore, the PAT thin film could be obtained for the experiments.

\subsection{Microstructure Analysis}

The crystalline structure of the PAT thin film was analyzed by a grazing-angle x-ray diffractometry (GAXRD, Rigaku 2200, Japan). Moreover, the interface microstructure was also identified by a high-resolution transmission electron microscope (TEM; JEOL-2100, Japan). The focused ion beam system was applied to prepare an electron transparency area of the cross-sectional TEM sample.

\subsection{Cell Culturing}

In order to evaluate the mechanobiological reaction of MG-63 cells and NIH3T3 cells, the specimens with a dimension of $10 \mathrm{~mm} \times 10 \mathrm{~mm} \times 1 \mathrm{~mm}$ were subjected to cell culture. Before culturing the cells, the specimens were rinsed three times using a mixture solution of $0.1 \mathrm{M}$ phosphate-buffered saline (pH 7.2) and Dulbecco's modified Eagle's medium (DMEM, Gibco). Afterward, the specimens were placed into the 24-well polystyrene plate and sterilized with ultraviolet rays for $24 \mathrm{~h}$. The DMEM containing fetal bovine serum $(10 \%)$, streptomycin $(100 \mathrm{mg} / \mathrm{mL})$, and penicillin $(100 \mathrm{units} / \mathrm{mL})$ was used as the culture medium. A density of $3 \times 10^{4} / \mathrm{cm}^{2}$ cell suspension (MG-63 cell and NIH3T3) was 
added to the plate, respectively. Then, the specimens were cultured at $37^{\circ} \mathrm{C}$ for $4 \mathrm{~h}, 8 \mathrm{~h}, 24 \mathrm{~h}$, and $72 \mathrm{~h}$ in a humidified atmosphere of $95 \%$ air and $5 \% \mathrm{CO}_{2}$. Subsequently, the cells on the treated surface were observed via a scanning electron microscope (SEM; JEOL JSM-6500F, Tokyo, Japan) at different magnifications to evaluate their morphology, adhesion, and proliferation features.

\subsection{Biosensing Capability}

The top $\mathrm{Cu}$ electrodes (3500 $\mathrm{nm}$ in thickness) were finally deposited on the surface of the investigated specimens through the sputtering system and patterned to measure current-voltage (IV). Both capacitors of $\mathrm{Cu} / \mathrm{PAT}$ and $\mathrm{Cu} / \mathrm{cell} / \mathrm{PAT}$ were used to investigate the capacitor capability of the PAT film against the cell reaction by electrical analysis. An HP 4145B semiconductor parameter analyzer (Palo Alto, CA, USA) at a reverse bias of $-5 \mathrm{~V}$ was adopted to measure the leakage current of the investigated specimens. An average value of 30 specimens was performed to obtain the leakage current density at the $300 \mu \mathrm{m} \times 300 \mu \mathrm{m}$ detected area. The diode leakage current was measured after culturing for various periods.

\subsection{Stress Variation Measurement}

Stress measurements were taken by means of a Toho FLX 2320-S thin film stress measurement system (Chicago, IL, USA). The stress was determined using the Stony's Equation (1).

$$
\sigma_{f}=\left(\frac{E}{1-v}\right)_{s} \frac{t_{s}^{2}}{6 r t_{f}}
$$

where the symbols $t_{f}, t_{s}$, and $r$ refer to film thickness, substrate thickness, and film curvature, respectively. The Stony's equation shows that by measuring the curvature and the thickness of the film and the substrate, and by knowing the Young's modulus $(E)$ and Poisson's ratio $(v)$ of the substrate, we can determine the stress $\left(\sigma_{f}\right)$ in the film. The curvature can be measured by laser interference or by stylus profiling.

\section{Results and Discussion}

The GAXRD and cross-sectional TEM of the PAT film were investigated as shown in Figure 1. The GAXRD pattern and TEM micrograph analysis of the PAT film showed a diffraction peak of (002), which confirmed that the crystalline structure of the PAT film belonged to the hexagonal close-packed (hcp) structure. The cross-sectional TEM image also obviously indicated the formation of nanopolycrystalline grains $(\sim 50 \mathrm{~nm})$ in the PAT film. Similar results have been reported by Ou et al. [21]. Figure 2 depicts the high-magnification SEM and cross-sectional TEM images of MG-63 cells cultured for $72 \mathrm{~h}$ on the PAT film. Numerous filopodia are visible, as displayed in Figure 2a. Cells on the PAT film were more spread out and had filopodia that were longer and in greater number. Figure $2 b$ shows a TEM micrograph of the PAT film from the cross-sectional direction following cell culturing. The MG-63 cell (as indicated by the arrow and dash-line covered area) is well adhered and obviously a polygon with no prominent nuclei. After $72 \mathrm{~h}$ of culture, most of the cells began to differentiate along small irregular regions, and the cells were firmly adhered, flattened, and irregularly networked, demonstrating that the PAT film had great proliferation ability. 


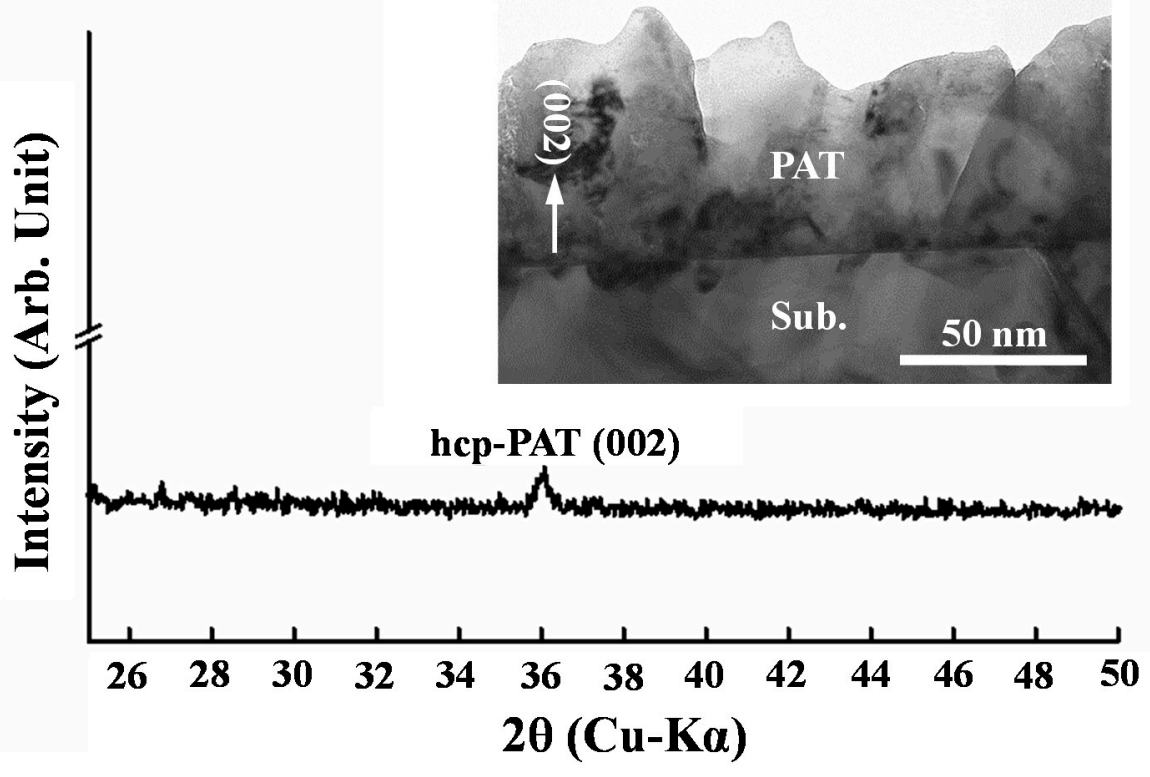

Figure 1. Cross-sectional bright-field TEM image and GAXRD pattern of the PAT film.

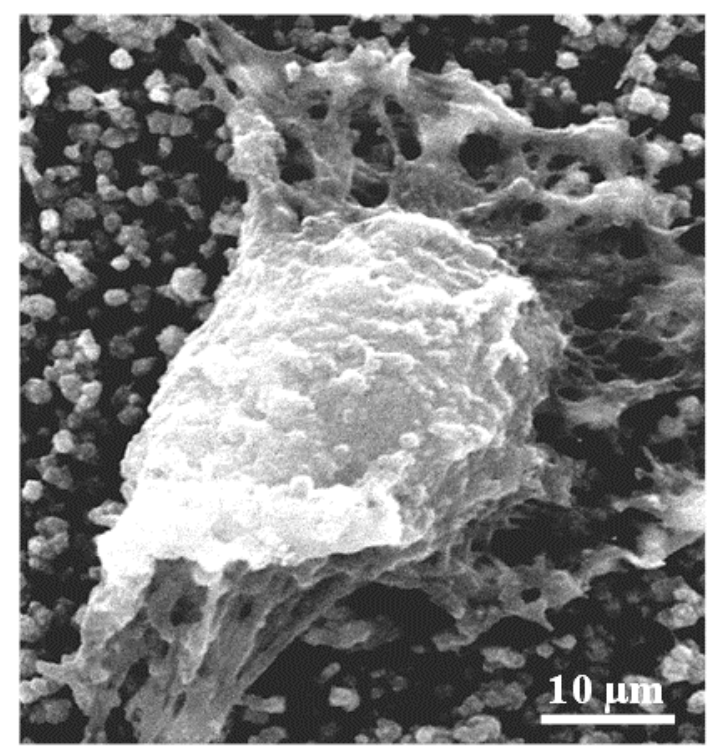

(a)

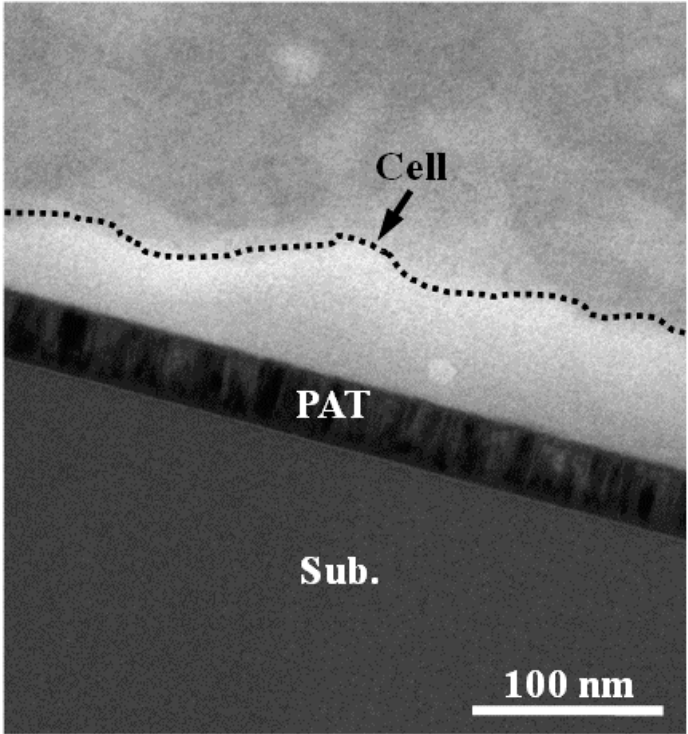

(b)

Figure 2. (a) SEM micrograph and (b) cross-sectional TEM image demonstrating cellular morphology on a hcp-PAT film after culturing for $72 \mathrm{~h}$ (MG-63 cell).

As mentioned, implants with a surface coating are well known to have a high degree of biocompatibility. After surface modification of the implants, they have better function and biocompatibility. Thus, surface modifications are recommended as coatings for implants that are in contact with blood. The adhesion of blood cells such as platelets, red blood cells, and leukocytes can be improved by surface treatment [22]. Compared with a smooth surface, an increase in the surface roughness from 0.2 to $0.5 \mathrm{~mm}$ (arithmetical mean roughness (Ra)) can enhance blood cell adhesion ability [23]. Moreover, the nitrided implants can significantly promote the adsorption of human salivary albumin. This feature proved that human albumin has a high affinity for the nitriding-treated surfaces [24]. Based on the above discussion, it revealed that changes in surface properties caused by surface modifications play a vital role in biocompatibility [13]. Hence, the surface characteristics and biocompatibility of implants could be potentially improved by the nanopolycrystalline PAT coating. 
After culturing for $72 \mathrm{~h}$, the PAT film with MG-63 cells exhibited a severe leakage current density at $150 \mathrm{kV} / \mathrm{cm}$ in comparison to the PAT film without MG-63 cells, as shown in Figure 3. In particular, the bone cell/PAT specimen showed a high percentage of breakdown specimen $(\sim 80 \%)$ at $150 \mathrm{kV} / \mathrm{cm}$, revealing that the dielectric layer is passed by most of the currents before the capacitor breakdown. Similar results were also observed in the previous studies [11,14]. Cells on the PAT film surface were also observed by a cross-sectional microstructure image, as shown in Figure 4. Slit-like microvoids (as indicated by the black arrow) were found across the cell/PAT film. However, no slit-like microvoids could be observed in the PAT film without cells. This feature indicates that the failure is caused by mechanical reasons, and not from electrical reasons. The microvoids act as an electrical path that ultimately breaks down the capacitor with a low applied voltage. This is probably due to the PAT film undergoing some osteogenic reactions such as proliferation and differentiation. The formation of microvoids can be used to realize the stress variation of the PAT biosensing capacitor.

The calculation and analysis results exhibited that the state of stress altered from compressive stress to tensile stress at the PAT film and the bone cell layer boundary, as shown in Figure 5. Based on the stress variation analysis, the bone cell reacted with the thin film containing stress flow resulted in the formation of defects (voids, dislocation, and slips). As discovered in all specimens, bone cells causing the stress formation seem to be large enough to induce the mechanical failure of the biosensing capacitor with microvoids. Similar results have been observed in previous studies [11,14]. It is well known that surface atoms are usually bonded to internal atoms through chemical bonding. If surface atoms are to be released, the bonds to internal atoms must be broken. Surface activation energy is often required to break these bonds. During cell differentiation and proliferation, the equivalent activation energy formed by a mechanobiological reaction happens to endure the surface activation energy of the PAT film. The equivalent activation energy generated from cell differentiation and proliferation is named as the cell activation energy (CAE). In the mechanobiological reaction, the CAE is the redox potential in the mechanobiological reaction of MG-63 cells and NIH3T3 cells in a multilayered PAT film. The lattice defects and/or initial stress of PAT film have all been found to affect the cell differentiation and proliferation. Moreover, the surface activation energy was reduced as the grain boundaries and sub-grain boundaries of the PAT film increased. The nanopolycrystalline $\{002\}$ PAT film is preferred and reacts faster than the $\{111\}$ planes, forming a mechanobiological reaction. Thus, the mechanobiological reaction of cell differentiation and proliferation not only causes osseo/osteointegration, but also decreases the surface activation energy, then enhancing bone remodeling. The formation of a nanopolycrystalline $\{002\}$ PAT film is believed to promote biocompatibility, enhancing osseointegration. Therefore, the mechanobiological formation of PAT on a Ti implant with and without cell differentiation and proliferation must be discussed at length.

Furthermore, the adhesion, morphology, and proliferation of MG-63 cells on the surface of the PAT film led to the following results: first, the cells exhibited a higher thickness, and a nanometer-scale roughness favored the formation of longer and more filopodia than that of the NIH3T3 cell. The MG-63 cells and NIH3T3 cells responded to the PAT surface topography with adhesion, altered morphology, and proliferation. Additionally, an excellent biosensing and a biocompatible film should offer a superior surface topography that allows for rapid bone healing. In the stress analysis results, the PAT film was capable of enhancing more differentiation and proliferation of MG-63 cells than that of NIH3T3 cells over the same period of time. This revealed that the enhancement of the proliferation capability of MG-63 bone cells can enhance osseointegration and re-osseointegration. In addition, it is also an important factor in the postoperative healing and bone remodeling of cortical bone [25]. The biosensing effect of the biomechanical reaction on an osseointegrated implant with PAT film was evaluated efficiently using a biosensing capacitor and a representation of the implant-to-bone and stress-transfer performances. Therefore, the PAT film could potentially be applied to monitor implant osseointegration and stability using wireless technology in the near future. 


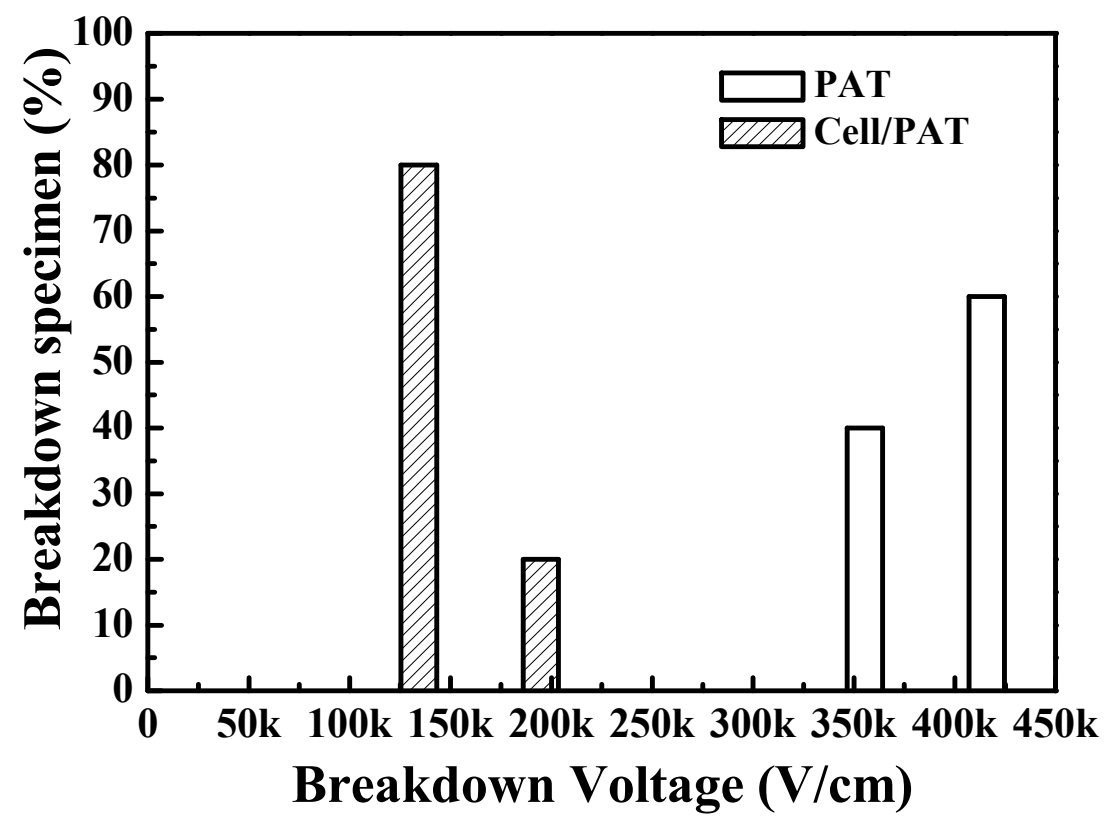

Figure 3. Histograms of the distributions of breakdown field for the PAT biosensing capacitor with (MG-63 cell cultured for $72 \mathrm{~h}$ ) and without cell cultures.

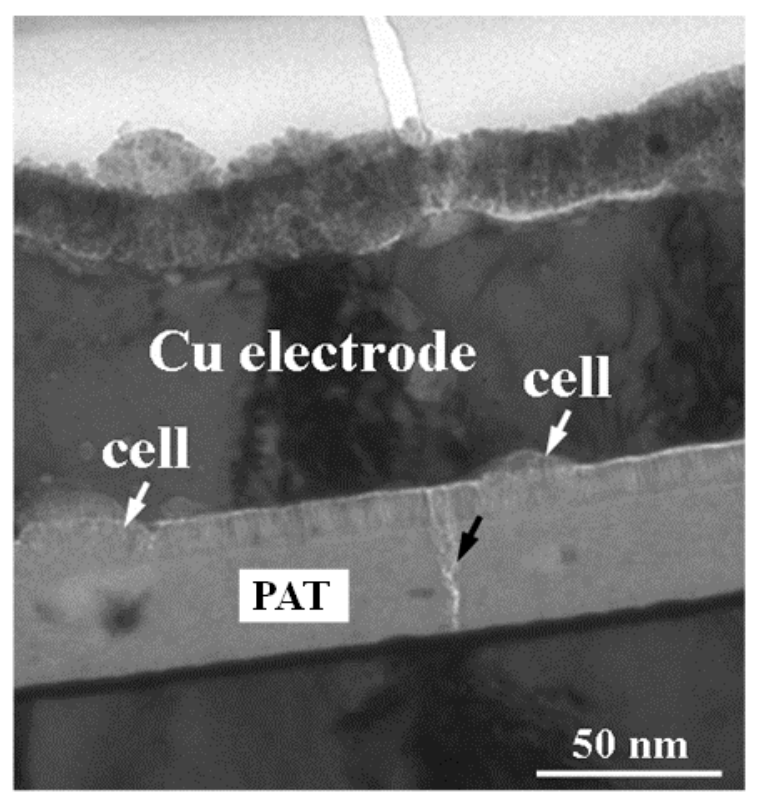

Figure 4. The cross-sectional TEM micrograph of the PAT biosensing capacitor with cells. 


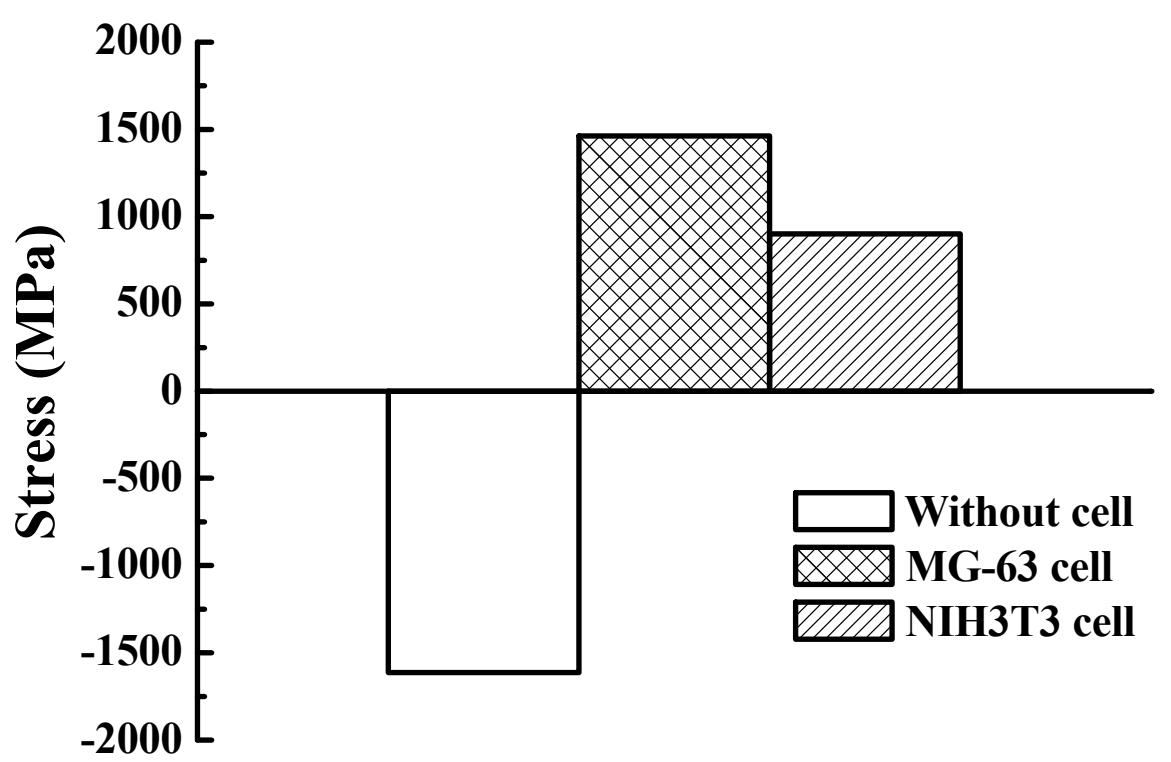

Figure 5. The stress state of the PAT film before and after being cultured with MG-63 and NIH3T3 cells.

\section{Conclusions}

The PAT thin film was fabricated as a biocompatible film to be used for osseointegration biosensing on an implant. The MG-63 cells were more dispersed and displayed longer and more filopodia than the NIH3T3 cells on the PAT film. It was obvious that the PAT film had excellent biocompatibility. The stress change during proliferation and differentiation of MG63 cells was more pronounced than those of the NIH3T3 cells. The stress altered the cell morphology, proliferation, and adhesion will exist as the piezoelectric effect on the PAT film surface. It is believed that biomedical devices can be utilized to monitor the piezoelectric effect induced by osseointegration, re-osseointegration, and tissue healing in situ.

Author Contributions: Investigation and Writing-original draft, M.-S.H.; Writing-original draft, S.-Y.Y.; Data curation, P.-C.C. and C.-C.H.; Project administration, B.-H.H.; Conceptualization, T.S.; Validation, F.-T.P.; Writing - review \& editing, C.-Y.W. and W.-C.L. All authors have read and agreed to the published version of the manuscript.

Funding: This research received no external funding.

Conflicts of Interest: The authors report no conflicts of interest in this work.

\section{References}

1. Tsai, M.H.; Haung, C.F.; Shyu, S.S.; Chou, Y.R.; Lin, M.H.; Peng, P.W.; Ou, K.L.; Yu, C.H. Surface modification induced phase transformation and structure variation on the rapidly solidified recast layer of titanium. Mater. Charact. 2015, 106, 463-469. [CrossRef]

2. Hou, P.J.; Ou, K.L.; Wang, C.C.; Huang, C.F.; Ruslin, M.; Sugiatno, E.; Yang, T.S.; Chou, H.H. Hybrid micro/nanostructural surface offering improved stress distribution and enhanced osseointegration properties of the biomedical titanium implant. J. Mech. Behav. Biomed. 2018, 79, 173-180. [CrossRef]

3. Chiang, H.J.; Chou, H.H.; Ou, K.L.; Sugiatno, E.; Ruslin, M.; Waris, R.A.; Huang, C.F.; Liu, C.M.; Peng, P.W. Evaluation of Surface Characteristics and Hemocompatibility on the Oxygen Plasma-Modified Biomedical Titanium. Metals 2018, 8, 513. [CrossRef]

4. Wu, C.M.; Liu, C.M.; Ou, K.L.; Chiang, H.J.; Sugiatno, E.; Wu, C.H.; Yen, H.J.; Chou, H.H. Nanostructured titanium dioxide layer combined with reactive functional groups as a promising biofunctional surface for biomedical applications. Ceram. Int. 2019, 45, 9712-9718. [CrossRef]

5. Cheng, H.C.; Lee, S.Y.; Chen, C.C.; Shyng, Y.C.; Ou, K.L. Titanium nanostructural surface processing for improved biocompatibility. Appl. Phys. Lett. 2006, 89. [CrossRef] 
6. Chen, S.L.; Lin, M.H.; Chen, C.C.; Ou, K.L. Effect of electro-discharging on formation of biocompatible layer on implant surface. J. Alloys Compd. 2008, 456, 413-418. [CrossRef]

7. Ou, K.L.; Lin, C.T.; Chen, S.L.; Huang, C.F.; Cheng, H.C.; Yeh, Y.M.; Lin, K.H. Effect of multi-nano-titania film on proliferation and differentiation of mouse fibroblast cell on titanium. J. Electrochem. Soc. 2008, 155, E79-E84. [CrossRef]

8. Ou, K.L.; Chen, C.C.; Lin, C.T.; Chen, C.S.; Lin, C.C.; Lee, S.Y. Application of aluminum nitride thin film on biosensing of cell differentiation. J. Electrochem. Soc. 2007, 154, P11-P15. [CrossRef]

9. Kaluderovic, M.R.; Krajnovic, T.; Maksimovic-Ivanic, D.; Graf, H.L.; Mijatovic, S. Ti-SLActive and TiZr-SLActive Dental Implant Surfaces Promote Fast Osteoblast Differentiation. Coatings 2017, 7, 102. [CrossRef]

10. Pachauri, P.; Bathala, L.R.; Sangur, R. Techniques for dental implant nanosurface modifications. J. Adv. Prosthodont. 2014, 6, 498-504. [CrossRef]

11. Ou, K.L.; Shih, Y.H.; Huang, C.F.; Chen, C.C.; Liu, C.M. Preparation of bioactive amorphous-like titanium oxide layer on titanium by plasma oxidation treatment. Appl. Surf. Sci. 2008, 255, 2046-2051. [CrossRef]

12. Haimov, H.; Yosupov, N.; Pinchasov, G.; Juodzbalys, G. Bone Morphogenetic Protein Coating on Titanium Implant Surface: A Systematic Review. J. Oral Maxillofac. Res. 2017, 8. [CrossRef] [PubMed]

13. Solar, R.J.; Pollack, S.R.; Korostoff, E. In vitro corrosion testing of titanium surgical implant alloys: An approach to understanding titanium release from implants. J. Biomed. Mater. Res. 1979, 13, 217-250. [CrossRef] [PubMed]

14. Chen, C.C.; Lin, C.T.; Lee, S.Y.; Lin, L.H.; Huang, C.F.; Ou, K.L. Biosensing of biophysical characterization by metal-aluminum nitride-metal capacitor. Appl. Surf. Sci. 2007, 253, 5173-5178. [CrossRef]

15. Nishimura, I. Genetic networks in osseointegration. J. Dent. Res. 2013, 92, 109S-118S. [CrossRef]

16. Smeets, R.; Stadlinger, B.; Schwarz, F.; Beck-Broichsitter, B.; Jung, O.; Precht, C.; Kloss, F.; Grobe, A.; Heiland, M.; Ebker, T. Impact of Dental Implant Surface Modifications on Osseointegration. Biomed. Res. Int. 2016. [CrossRef]

17. Agarwal, R.; Garcia, A.J. Biomaterial strategies for engineering implants for enhanced osseointegration and bone repair. Adv. Drug Deliv. Rev. 2015, 94, 53-62. [CrossRef]

18. Gao, X.; Fraulob, M.; Haiat, G. Biomechanical behaviours of the bone-implant interface: A review. J. $R$. Soc. Interface 2019, 16. [CrossRef]

19. Duan, Y.; Ma, W.; Li, D.; Wang, T.; Liu, B. Enhanced osseointegration of titanium implants in a rat model of osteoporosis using multilayer bone mesenchymal stem cell sheets. Exp. Ther. Med. 2017, 14, 5717-5726. [CrossRef]

20. Fraioli, R.; Rechenmacher, F.; Neubauer, S.; Manero, J.M.; Gil, J.; Kessler, H.; Mas-Moruno, C. Mimicking bone extracellular matrix: Integrin-binding peptidomimetics enhance osteoblast-like cells adhesion, proliferation, and differentiation on titanium. Colloids Surf. 2015, 128, 191-200. [CrossRef]

21. Kasemo, B. Biocompatibility of titanium implants: Surface science aspects. J. Prosthet. Dent. 1983, 49, 832-837. [CrossRef]

22. Park, J.Y.; Gemmell, C.H.; Davies, J.E. Platelet interactions with titanium: Modulation of platelet activity by surface topography. Biomaterials 2001, 22, 2671-2682. [CrossRef]

23. Maitz, M.F.; Pham, M.T.; Wieser, E. Blood compatibility of titanium oxides with various crystal structure and element doping. J. Biomater. Appl. 2003, 17, 303-319. [CrossRef] [PubMed]

24. Lin, C.C.; Cheng, H.C.; Huang, C.F.; Lin, C.T.; Lee, S.Y.; Chen, C.S.; Ou, K.L. Enhancement of biocompatibility on bioactive titanium surface by low-temperature plasma treatment. Jpn. J. Appl. Phys. 2005, 44, 8590-8598. [CrossRef]

25. Stanford, C.M.; Brand, R.A. Toward an understanding of implant occlusion and strain adaptive bone modeling and remodeling. J. Prosthet. Dent. 1999, 81, 553-561. [CrossRef]

(C) 2020 by the authors. Licensee MDPI, Basel, Switzerland. This article is an open access article distributed under the terms and conditions of the Creative Commons Attribution (CC BY) license (http://creativecommons.org/licenses/by/4.0/). 